\title{
Lung function in the late postoperative phase and influencing factors in patients undergoing pulmonary lobectomy
}

\author{
Ryoichi Matsumoto ${ }^{1}$, Shinzo Takamori ${ }^{1}$, Shintaro Yokoyama ${ }^{1}$, Toshihiro Hashiguchi ${ }^{1}$, Daigo Murakami ${ }^{1}$, \\ Koichi Yoshiyama ${ }^{1}$, Tatsuya Nishi ${ }^{1}$, Masaki Kashihara ${ }^{1}$, Masahiro Mitsuoka ${ }^{1}$, Ryozo Hayashida ${ }^{2}$, Tatsuyuki \\ Kakuma $^{3}$, Yoshito Akagi ${ }^{1}$ \\ ${ }^{1}$ Department of Surgery, Kurume University School of Medicine, Kurume, Japan; ${ }^{2}$ Department of Surgery, Oita Prefecture Saiseikai Hita Hospital, \\ Hita, Japan; ${ }^{3}$ Biostatistics Center, Kurume University, Kurume, Japan \\ Contributions: (I) Conception and design: R Matsumoto, S Takamori; (II) Administrative support: None; (III) Provision of study materials or \\ patients: R Matsumoto, S Takamori, T Hashiguchi, D Murakami, K Yoshiyama, T Nishi, M Kashihara, M Mitsuoka, R Hayashida; (IV) Collection \\ and assembly of data: R Matsumoto, S Takamori, S Yokoyama, R Hayashida; (V) Data analysis and interpretation: R Matsumoto, S Takamori, S \\ Yokoyama, T Kakuma; (VI) Manuscript writing: All authors; (VII) Final approval of manuscript: All authors. \\ Correspondence to: Shinzo Takamori, MD, PhD. Department of Surgery, Kurume University School of Medicine, 67 Asahi-machi, Kurume 8300011, \\ Japan. Email: stakam@med.kurume-u.ac.jp.
}

Background: Lung function in the late postoperative phase after pulmonary lobectomy is insufficiently characterized. This study aimed to appraise lung function in the late postoperative phase according to vital capacity (VC) and forced expiratory volume in 1 second (FEV1) in patients who underwent pulmonary lobectomy.

Methods: Pre- and postoperative VC and FEV1 were reviewed in 112 patients who underwent pulmonary lobectomy. Postoperative lung volume was assessed $>1$ year after surgery. Postoperative decreases in VC and FEV1 were compared with preoperative predicted values among patients who underwent resection of specific lobe. Determinants effecting a decrease in lung function were also investigated.

Results: A mean postoperative decreased VC of $10.5 \% \pm 1.8 \%$ was recorded in patients who underwent right upper lobectomy (RU), $7.2 \% \pm 1.5 \%$ for right middle lobectomy $(\mathrm{RM}), 14.3 \% \pm 2.3 \%$ for right lower lobectomy (RL), $16.6 \% \pm 3.0 \%$ for left upper lobectomy (LU), and $14.7 \% \pm 2.5 \%$ for left lower lobectomy (LL). Corresponding FEV1 values were $14.8 \% \pm 1.8 \%$ for RU, $11.9 \% \pm 4.0 \%$ for RM, $14.9 \% \pm 2.3 \%$ for RL, $17.9 \% \pm 2.9 \%$ for $\mathrm{LU}$, and $15.1 \% \pm 2.4 \%$ for LL. The actual decreasing rate of $\mathrm{VC}$ was overestimated in patients who underwent RU, RL, LU, and LL. In contrast, FEV1 was overestimated only in patients who underwent RL and LL. Patients with chronic obstructive pulmonary disease (COPD) exhibited significantly better preservation of FEV1.

Conclusions: Patients scheduled for RL and LL, or those with COPD, appeared to exhibit preserved lung function in the late postoperative phase after pulmonary lobectomy.

Keywords: Pulmonary lobectomy; lung function; vital capacity (VC); forced expiratory volume in 1 second (FEV1); decreasing rate

Submitted Jan 04, 2018. Accepted for publication Apr 16, 2018.

doi: $10.21037 /$ jtd.2018.05.27

View this article at: http://dx.doi.org/10.21037/jtd.2018.05.27 


\section{Introduction}

Pulmonary lobectomy is a common surgical intervention with consensus support as a standard procedure for curable treatment of primary non-small cell lung cancer (NSCLC) (1). However, resection of lung parenchyma impairs some reserves of lung function, possibly leading to inability to tolerate exercise because alveolar units cannot be reproduced to fully compensate for lost lung volume. Vital capacity (VC) and forced expiratory volume in 1 second $\left(\mathrm{FEV}_{1}\right)$ are representative indexes of lung function, and are routinely measured before surgery to select suitable candidates for pulmonary lobectomy. Therefore, surgeons are required to predict loss of lung volume quantified by these measures, and also subsequent recovery caused by morphological expansion of the remaining lung.

Previous studies have assessed lung function after pulmonary lobectomy, and have determined that $\mathrm{VC}$ and $\mathrm{FEV}_{1}$ decrease for a period of approximately 6 months after surgery (2-4). Other investigations have reported that these values gradually recover after 6 months and then are maintained 12 months after surgery (5). However, these reports included a relatively small sample sizes. Moreover, details of lung function $>1$ year after surgery remain uncertain.

The aim of this study was to compare pre- and postoperative values of $\mathrm{VC}$ and $\mathrm{FEV}_{1}$ in the late postoperative phase ( $>1$ year after surgery) in a comparatively larger sample size of patients who underwent pulmonary lobectomy. In addition, patient characteristics, including comorbidities that potentially affect lung function after lobectomy, were also investigated.

\section{Methods}

\section{Patients}

The present study included patients who underwent pulmonary lobectomy through thoracotomy with anteroaxillar incision primarily for NSCLC or other pulmonary diseases at Kurume University Hospital (Kurume, Japan) or Oita Prefecture Saiseikai Hita Hospital (Hita, Japan) between March 2000 and June 2014. Patients older than 80 years of age, with poor physical activity (Eastern Cooperative Oncology Group performance status equal to or worse than 2), and those who received perioperative chemo- or radiotherapy, except postoperative oral uracil and tegafur, were excluded because of the potential for inadequate performance in spirometry test due to physical dysfunction (6). In addition, patients who were lost to follow-up were excluded; ultimately, 112 patients were enrolled in the present analysis. Histological subtypes of NSCLC were assigned according to the classification of the World Health Organization (7). The study was approved by the Institutional Research Ethics Committee of Kurume University (No. 17065) and Oita Prefecture Saiseikai Hita Hospital (No. 26-11), and all patients provided informed written consent to participate.

\section{Assessment of pulmonary function}

Lung function was evaluated using spirometry according to American Thoracic Society/European Respiratory Society criteria (8). To calculate predicted postoperative VC and $\mathrm{FEV}_{1}$, the lungs were divided into a total of 42 subsegments. The subsegments were then assessed for obstruction using computed tomography imaging or bronchoscopy, and predicted postoperative $\mathrm{VC}$ and $\mathrm{FEV}_{1}$ were calculated based on the number of functioning/unobstructed subsegments that would be removed during surgery $(9,10)$. The predicted postoperative value of $\mathrm{VC}$ and $\mathrm{FEV}_{1}$ were calculated using the following equation:

Preoperative value $\times[1-(b-n) /(42-n)](L)$,

In which $\mathrm{n}$ and $\mathrm{b}$ are the numbers of obstructed segments and total segments, respectively (5). In addition, decreasing rate, which was defined as the decrease in the proportion of observed postoperative lung volume compared with preoperative lung volume, was similarly calculated as follows:

[(preoperative value - postoperative value)/preoperative value] $\times 100(\%)$.

Patient characteristics potentially effecting a decrease in pulmonary function were also analyzed and included sex, smoking habits, resected lobe, tumor histological subtype, interval between pre- and postoperative measurement, and comorbidities. In the present study, the presence of chronic obstructive pulmonary disease (COPD) as a comorbidity was defined according to the Global Initiative for Obstructive Lung Disease (GOLD) criteria (11).

\section{Statistical analysis}

Statistical comparisons between the resected lobe and clinicopathological features were evaluated using Wilcoxon rank sum tests, paired $t$-tests, and Fisher's exact tests. The paired $t$-test was performed to compare preoperative and postoperative lung volume, as well as predicted and observed decreasing rates of $\mathrm{VC}$ and $\mathrm{FEV}_{1}$. Simple regression and 
Table 1 Patient characteristics based on the resected lobes

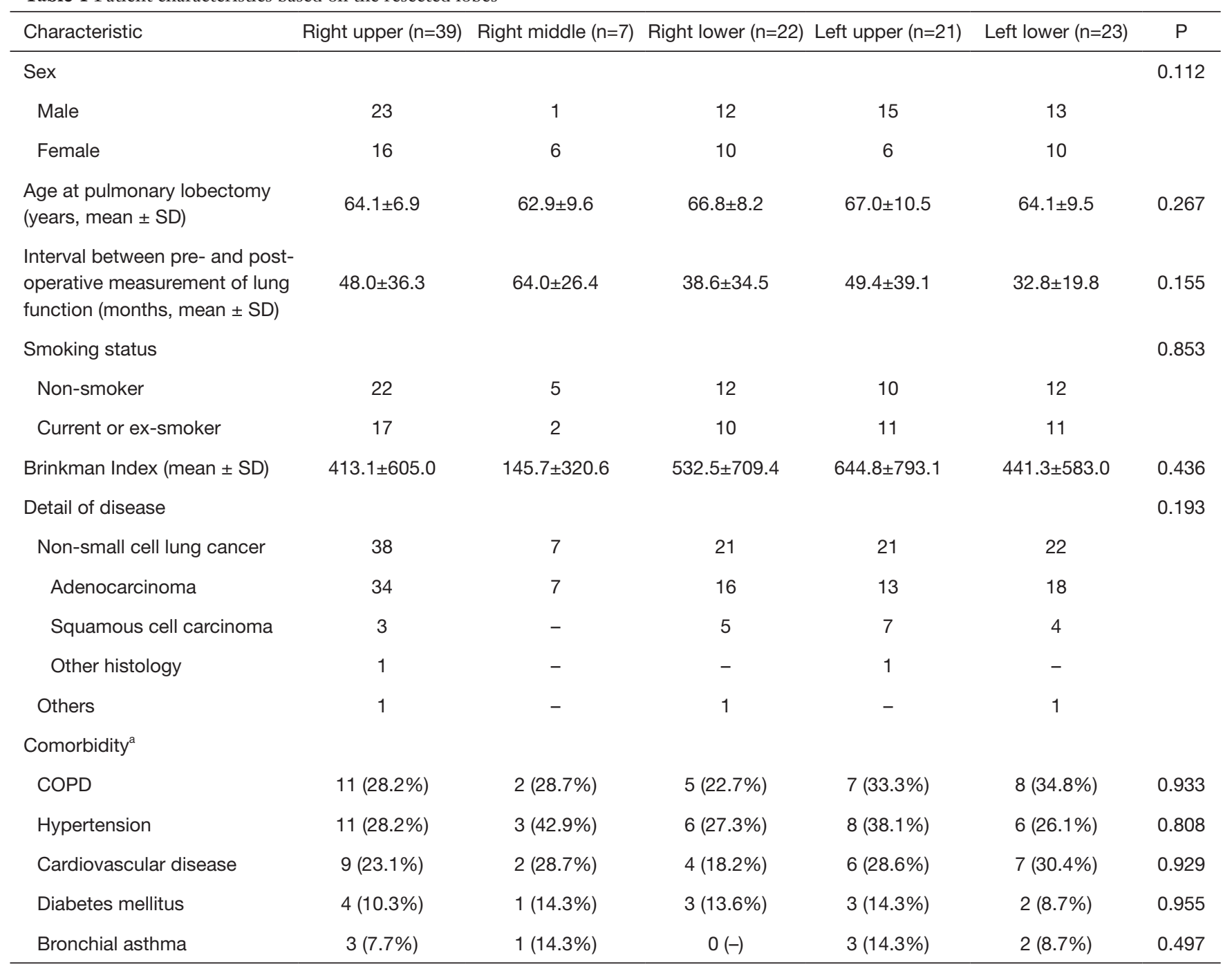

${ }^{\mathrm{a}}$, thirty-four cases are redundant. SD, standard deviation; COPD, chronic obstructive pulmonary disease.

stepwise multiple regression models were used in univariate and multivariate analyses to examine the influence of each characteristic in the observed decreasing rate in $\mathrm{VC}$ and $\mathrm{FEV}_{1} ; \mathrm{P}<0.05$ was considered to be statistically significant. Statistical analyses were all performed using JMP Pro version 11 (SAS Institute Inc., Cary, NC, USA).

\section{Results}

\section{Patient characteristics}

Table 1 summarizes the characteristics of the 112 patients enrolled in the present study according to the lobe that was resected. Subjects included 64 males and 48 females, with a mean age of 65.1 and 68.9 years at pre- and postoperative measurement of lung function, respectively. There were $61(54.5 \%)$ non-smokers and $51(45.5 \%)$ patients who had ever smoked, with a mean Brinkman Index of 469, which is defined as (number of cigarettes per day) $\times$ (number of years for which a person smoked) (12). Comorbidities included COPD in 33 (29.5\%) patients, hypertension in 34 (30.4\%), cardiovascular disease in 28 (25.0\%), diabetes mellitus in $13(11.6 \%)$, and bronchial asthma in $9(8.0 \%)$. There were no statistical differences in clinicopathological features of patients with regard to the resected lobe. 
Table 2 Quantitative analysis of pre- and post-operative $\mathrm{VC}$ and $\mathrm{FEV}_{1}$ in each lobe

\begin{tabular}{|c|c|c|c|c|c|c|c|c|}
\hline $\begin{array}{l}\text { Resected } \\
\text { lobe }\end{array}$ & \multicolumn{4}{|c|}{ VC } & \multicolumn{4}{|c|}{$\mathrm{FEV}_{1}$} \\
\hline Right middle & $2.69 \pm 0.20$ & $2.48 \pm 0.16$ & $7.2 \pm 1.5$ & 0.004 & $1.94 \pm 0.10$ & $1.71 \pm 0.12$ & $11.9 \pm 4.0$ & 0.036 \\
\hline Left lower & $3.36 \pm 0.17$ & $2.84 \pm 0.14$ & $14.7 \pm 2.5$ & $<0.001$ & $2.45 \pm 0.12$ & $2.07 \pm 0.12$ & $15.1 \pm 2.4$ & $<0.001$ \\
\hline
\end{tabular}

${ }^{\mathrm{a}}$, values are shown as mean \pm standard deviation. VC, vital capacity; FEV ${ }_{1}$, forced expiratory volume in 1 second.

Table 3 Comparisons between predicted and observed decreasing rates of $\mathrm{VC}$ and $\mathrm{FEV}_{1}$ after pulmonary lobectomy in each lobe

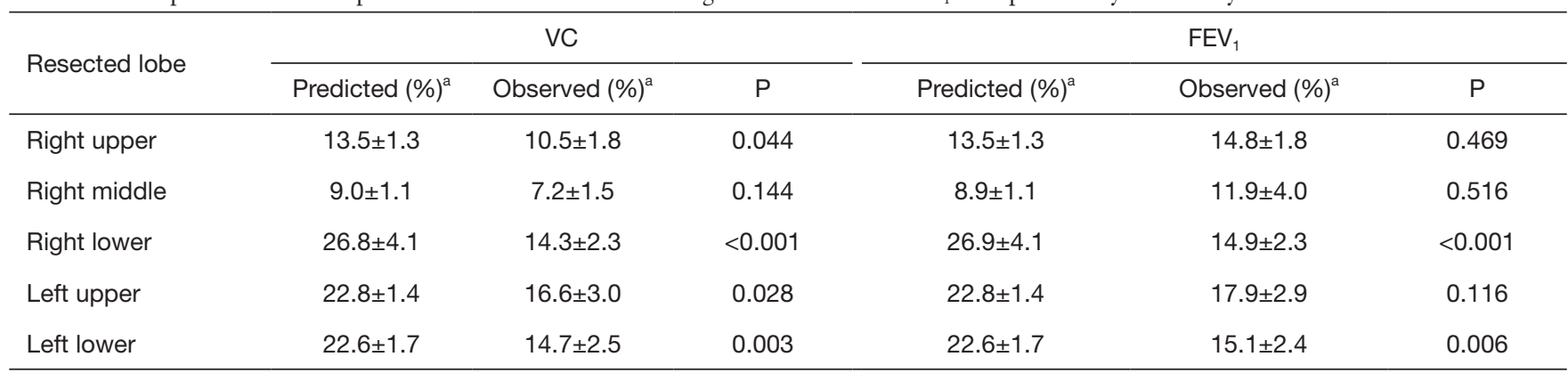

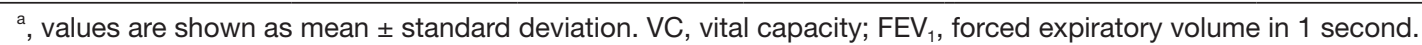

\section{Comparison between pre- and postoperative lung function after pulmonary lobectomy}

The mean interval from pre- to postoperative measurement of lung function was 44.3 months (range, 12-186 months). Calculated postoperative decreases in $\mathrm{VC}$ were $10.5 \% \pm 1.8 \%$ in patients who underwent right upper lobectomy (RU), $7.2 \% \pm 1.5 \%$ for right middle lobectomy (RM), $14.3 \% \pm 2.3 \%$ for right lower lobectomy (RL), $16.6 \% \pm 3.0 \%$ for left upper lobectomy (LU), and $14.7 \% \pm 2.5 \%$ for left lower lobectomy (LL). These postoperative decreases were all statistically significant, regardless of the lobe that was resected (Table 2). Similarly, calculated postoperative decreases in $\mathrm{FEV}_{1}$ were $14.8 \% \pm 1.8 \%$ in patients who underwent $\mathrm{RU}$, $11.9 \% \pm 4.0 \%$ for RM, $14.9 \% \pm 2.3 \%$ for RL, $17.9 \% \pm 2.9 \%$ for LU, and $15.1 \% \pm 2.4 \%$ for LL; patients underwent all procedures significantly suffered a notable loss of $\mathrm{FEV}_{1}$ after pulmonary lobectomy as observed in VC (Table 2).

\section{Discrepancy between predicted and observed lung function after pulmonary lobectomy}

The actual decreasing rate of $\mathrm{VC}$ in the late postoperative phase was overestimated in patients who underwent RU, RL, LU, and LL $(\mathrm{P}=0.044, \mathrm{P}<0.001, \mathrm{P}=0.028$, and $\mathrm{P}=0.003$, respectively) (Table 3). In contrast, a substantial decreasing rate in $\mathrm{FEV}_{1}$ was overestimated only in patients who underwent RL and LL, differences that were statistically significant $(\mathrm{P}<0.001$ and $\mathrm{P}=0.006$, respectively) (Table 3).

\section{Univariate and multivariate analysis of factors affecting decreasing volume of $V C$ and $F E V_{1}$}

Selected patient characteristics were assessed to determine whether any influenced the decreasing volume of $\mathrm{VC}$ and $\mathrm{FEV}_{1}$ (Table 4). In the analysis of $\mathrm{VC}$, none of the variables affected the decreasing volume in univariate analysis, which 
Table 4 Univariate and multivariate analysis of factors affecting decreasing volume of $\mathrm{VC}$ and $\mathrm{FEV}_{1}$

\begin{tabular}{|c|c|c|c|c|c|c|c|c|}
\hline \multirow{2}{*}{ Characteristic } & \multirow{2}{*}{ Group } & \multicolumn{3}{|c|}{ VC } & \multicolumn{3}{|c|}{$\mathrm{FEV}_{1}$} & \multirow{2}{*}{$\frac{\text { Multivariate }}{\mathrm{P}}$} \\
\hline & & Volume $(\mathrm{L})^{\mathrm{b}}$ & $95 \% \mathrm{Cl}$ & $\mathrm{P}$ & Volume $(\mathrm{L})^{\mathrm{b}}$ & $95 \% \mathrm{Cl}$ & $P$ & \\
\hline \multirow{2}{*}{$\begin{array}{l}\text { Smoking status } \\
\text { (Brinkman Index) }\end{array}$} & 0 & $0.41 \pm 0.06$ & & & $0.36 \pm 0.04$ & & & \\
\hline & 0-919 & $0.43 \pm 0.09$ & $(-0.19,0.23)$ & 0.876 & $0.41 \pm 0.07$ & $(-0.11,0.22)$ & 0.531 & \\
\hline \multirow[t]{2}{*}{ Detail of disease } & NSCLC & $0.46 \pm 0.04$ & & & $0.40 \pm 0.03$ & & & \\
\hline & Others & $0.39 \pm 0.20$ & $(-0.47,0.34)$ & 0.747 & $0.28 \pm 0.15$ & $(-0.43,0.19)$ & 0.437 & \\
\hline \multirow[t]{2}{*}{ Measurement interval $^{\mathrm{a}}$} & $12-36$ & $0.48 \pm 0.06$ & & & $0.33 \pm 0.04$ & & & \\
\hline & $37-59$ & $0.37 \pm 0.07$ & $(-0.29,0.08)$ & 0.255 & $0.41 \pm 0.06$ & $(-0.06,0.22)$ & 0.238 & \\
\hline \multirow[t]{2}{*}{ COPD } & Yes & $0.41 \pm 0.08$ & & & $0.26 \pm 0.06$ & & & \\
\hline & No & $0.45 \pm 0.05$ & $(-0.22,0.15)$ & 0.702 & $0.43 \pm 0.04$ & $(-0.30,-0.03)$ & 0.017 & 0.028 \\
\hline \multirow[t]{2}{*}{ Hypertension } & Yes & $0.36 \pm 0.07$ & & & $0.39 \pm 0.06$ & & & \\
\hline & No & $0.48 \pm 0.05$ & $(-0.29,0.06)$ & 0.204 & $0.36 \pm 0.04$ & $(-0.11,0.17)$ & 0.699 & \\
\hline \multirow{2}{*}{$\begin{array}{l}\text { Cardiovascular } \\
\text { disease }\end{array}$} & Yes & $0.45 \pm 0.08$ & & & $0.36 \pm 0.06$ & & & \\
\hline & No & $0.43 \pm 0.05$ & $(-0.17,0.22)$ & 0.803 & $0.38 \pm 0.04$ & $(-0.16,0.12)$ & 0.788 & \\
\hline \multirow[t]{2}{*}{ Diabetes mellitus } & Yes & $0.24 \pm 0.12$ & & & $0.25 \pm 0.09$ & & & \\
\hline & No & $0.47 \pm 0.05$ & $(-0.42,0.04)$ & 0.081 & $0.39 \pm 0.04$ & $(-0.33,0.06)$ & 0.162 & \\
\hline
\end{tabular}

${ }^{a}$, measurement interval is shown as terms between pre- and post-operative measurement of lung function (months); ${ }^{b}$, values are shown as mean \pm standard deviation. VC, vital capacity; FEV $_{1}$, forced expiratory volume in 1 second; NSCLC, non-small cell lung cancer; COPD, chronic obstructive pulmonary disease; $\mathrm{Cl}$, confidence interval.

precluded their inclusion in further multivariate analyses. In $\mathrm{FEV}_{1}$, the interval between pre- and postoperative measurement of lung function, and the presence of COPD, were determined to be significant factors affecting lung volume loss $(\mathrm{P}=0.022$ and $\mathrm{P}=0.017$, respectively). In the multivariate analysis, only the presence of COPD was identified as an independent factor influencing lung volume loss $(\mathrm{P}=0.028)$.

\section{Discussion}

In the present study, we demonstrated that $\mathrm{VC}$ and $\mathrm{FEV}_{1}$ clearly decreased after pulmonary lobectomy in the late postoperative phase ( $>1$ year after surgery). However, postoperative lung function in terms $\mathrm{VC}$ was better preserved than predicted in patients who underwent $\mathrm{RU}$, RL, LU, and LL. In addition, patients who underwent RL and LL exhibited significantly better preservation of $\mathrm{FEV}_{1}$ than predicted compared with those who underwent other procedures. The presence of COPD was identified as an independent predictor of better preservation of $\mathrm{FEV}_{1}$; specific profiles possibly affecting $\mathrm{VC}$, however, were not determined. These results are useful, and can be efficaciously used in the management of therapeutic strategies for NSCLC, particularly in decisions regarding surgical procedures.

Predicted postoperative $\mathrm{FEV}_{1}$ evaluated using spirometry is one of the measurements commonly applied to the 
prediction of postoperative mortality and morbidity after lung resection; therefore, it is widely used to select suitable candidates for pulmonary lobectomy $(10,13)$. Several approaches have similarly been adopted in recent years to predict residual lung function after pulmonary lobectomy, such as bronchial arteriography, pulmonary arteriography, pulmonary blood flow scintigraphy, and computed tomography-based lung volumetry (13-16). In contrast to these modalities, spirometry testing can be performed easily because of its long-standing and widespread availability (9). To further advance the understanding of processes that occur in the remaining lung after pulmonary lobectomy, additional studies investigating the correlation between results measured using spirometry testing and other modalities are required.

Our study clarified that pulmonary lobectomy necessarily entail significant decrease in $\mathrm{VC}$ and $\mathrm{FEV}_{1}$ after the procedure, even in the late phase $>1$ year after surgery compared with preoperative values. Previous studies have determined that lung function decreases in the early postoperative period after pulmonary lobectomy $(17,18)$, gradually recovers after 6 months, and then maintain 12 months after surgery $(2-5,19)$. Acknowledging these findings, our result serves as confirmation that, even after maximal recovery of lung function-reflected by compensation of the remaining lung-lung function after pulmonary lobectomy declines significantly compared with preoperative values. Furthermore, our results also showed that the decreasing volume in the late postoperative phase was larger when the interval between pre- and postoperative measurement of lung function was longer (Table 4), which is consistent with previous reports that maximal recovery after pulmonary lobectomy reached a peak approximately 1 year after surgery. Because of major concerns regarding poor respiratory function elicited by lung resection, which leads to postoperative long-term disability and poor quality of life, these results should be clearly reflected in patient selection for pulmonary lobectomy in clinical settings.

Patients who underwent RL and LL exhibited significantly better preservation of both $\mathrm{VC}$ and $\mathrm{FEV}_{1}$ than predicted $>1$ year after pulmonary lobectomy. Similarly, Ueda $e t$ al. reported that patients who underwent lower lobectomy exhibited significantly better lung function recovery than those who underwent upper lobectomy at 6-12 months after surgery, even though lower lobectomy required a volumetrically larger resection than upper lobectomy based on computed tomography-based functional lung volumetry and spirometry tests (20). They speculated that this result could be attributed to a compensatory response after lower lobectomy, which appeared to be more robust rather than that after upper lobectomy. Nevertheless, explanation for these results may be supported by some studies reporting that the compensatory inflation of the remaining lung after lobectomy was accompanied by increased pulmonary ventilation and perfusion of the remaining lung (21). Another study, involving adult dogs that included microscopic and radiologic evaluation, also demonstrated that compensatory expansion of the remaining lung is not simply a consequence of hyperinflation of the pre-existing alveolar septal tissue, but is accompanied by some increase in the vital lung tissue $(3,22)$. Although further studies are needed to identify detailed mechanisms of this outcome, it is highly likely that lung function recovery of $\mathrm{FEV}_{1}$ in patients who undergo $\mathrm{RL}$ or LL could be expected to be better preserved than that in those who undergo other procedures.

Univariate and multivariate analysis indicated that comorbid COPD was an independent favorable factor for the preservation of $\mathrm{FEV}_{1}$ in the late postoperative phase. Similarly, Baldi et al. reported that patients with mild to severe COPD exhibited better preservation of lung function in the late phase after pulmonary lobectomy than healthy patients (23). To investigate the basis of this result, we performed an additional analysis and demonstrated that the observed/predicted ratios of $F E V_{1}$ were higher in COPD patients compared with non-COPD patients. This finding is consistent with previous studies reporting minimal loss-or even improvement-of pulmonary function after lobar resection in COPD patients. On the other hand, other authors have speculated that a ventilation-perfusion relationship may be associated with this outcome $(24,25)$ and, therefore, patients with comorbid COPD can expect better preservation of $\mathrm{FEV}_{1}$ after pulmonary lobectomy in the late postoperative phase.

There were several limitations in this study. First, although we defined the lung function after lobectomy in the late postoperative phase as those $>1$ year following surgery, the interval between pre- and postoperative measurement of lung function varied among patients. This was caused by operational inconsistencies in our clinical follow-up, in which spirometry tests after surgery are not routinely performed. Further studies, including measurements of lung function in a synchronized, rigorously defined, period in the late phase following pulmonary lobectomy, are necessary to confirm our results because statistical biases may have originated from factors 
such as aging and the natural progression of underlying COPD. Second, this study did not analyze consecutive patients who underwent pulmonary lobectomy because some were lost to follow-up. To avoid a statistical bias due to patient selection, a prospective case series is necessary in future studies.

\section{Conclusions}

Our results demonstrated that lung function after pulmonary lobectomy inevitably decreased compared with the preoperative measurements, even after the recovery of lung function reached a peak after surgery. Furthermore, better preservation of respiratory function in the late postoperative phase can be expected in patients scheduled for RL and LL, as well as those with comorbid COPD.

\section{Acknowledgements}

None.

\section{Footnote}

Conflicts of Interest: The authors have no conflicts of interest to declare.

Ethical Statement: The study was approved by the Institutional Research Ethics Committee of Kurume University (No. 17065) and Oita Prefecture Saiseikai Hita Hospital (No. 26-11), and all patients provided informed written consent to participate.

\section{References}

1. Ginsberg RJ, Rubinstein LV. Randomized trial of lobectomy versus limited resection for T1 N0 non-small cell lung cancer. Lung Cancer Study Group. Ann Thorac Surg 1995;60:615-22; discussion 622-3.

2. Nezu K, Kushibe K, Tojo T, et al. Recovery and limitation of exercise capacity after lung resection for lung cancer. Chest 1998;113:1511-6.

3. Ali MK, Ewer MS, Atallah MR, et al. Regional and overall pulmonary function changes in lung cancer. Correlations with tumor stage, extent of pulmonary resection, and patient survival. J Thorac Cardiovasc Surg 1983;86:1-8.

4. Bolliger CT, Jordan P, Soler M, et al. Pulmonary function and exercise capacity after lung resection. Eur Respir J 1996;9:415-21.
5. Funakoshi Y, Takeda S, Sawabata N, et al. Long-term pulmonary function after lobectomy for primary lung cancer. Asian Cardiovasc Thorac Ann 2005;13:311-5.

6. Oken MM, Creech RH, Tormey DC, et al. Toxicity and response criteria of the Eastern Cooperative Oncology Group. Am J Clin Oncol 1982;5:649-55.

7. Travis WD, Brambilla E, Burke AP, et al. editors. WHO Classification of Tumours of the Lung, Pleura, Thymus and Heart. 4th ed. Lyon, France: IARC, 2015.

8. American Thoracic Society; European Respiratory Society. ATS/ERS Statement on respiratory muscle testing. Am J Respir Crit Care Med 2002;166:518-624.

9. Nakahara K, Monden Y, Ohno K, et al. A method for predicting postoperative lung function and its relation to postoperative complications in patients with lung cancer. Ann Thorac Surg 1985;39:260-5.

10. British Thoracic Society and Society of Cardiothoracic Surgeons of Great Britain and Ireland Working Party. BTS guidelines: guidelines on the selection of patients with lung cancer for surgery. Thorax 2001;56:89-108.

11. Vestbo J, Hurd SS, Agusti AG, et al. Global strategy for the diagnosis, management, and prevention of chronic obstructive pulmonary disease: GOLD executive summary. Am J Respir Crit Care Med 2013;187:347-65.

12. Brinkman GL, Coates EO, Jr. The effect of bronchitis, smoking, and occupation on ventilation. Am Rev Respir Dis 1963;87:684-93.

13. Kristersson S, Lindell SE, Svanberg L. Prediction of pulmonary function loss due to pneumonectomy using 133 Xe-radiospirometry. Chest 1972;62:694-8.

14. Kristersson S, Arborelius M Jr, Jungquist G, et al. Prediction of ventilatory capacity after lobectomy. Scand J Respir Dis 1973;54:315-25.

15. Arborelius M Jr, Kristersson S, Lindell SE, et al. 133 Xeradiospirometry and extension of lung cancer. Scand J Respir Dis 1971;52:145-52.

16. Sengul AT, Sahin B, Celenk C, et al. Postoperative lung volume change depending on the resected lobe. Thorac Cardiovasc Surg 2013;61:131-7.

17. Varela G, Brunelli A, Rocco G, et al. Predicted versus observed FEV1 in the immediate postoperative period after pulmonary lobectomy. Eur J Cardiothorac Surg 2006;30:644-8.

18. Brunelli A, Refai M, Salati M, et al. Predicted versus observed FEV1 and DLCO after major lung resection: a prospective evaluation at different postoperative periods. Ann Thorac Surg 2007;83:1134-9.

19. Mariano-Goulart D, Barbotte E, Basurko C, et al. 
Accuracy and precision of perfusion lung scintigraphy versus $133 \mathrm{Xe}$-radiospirometry for preoperative pulmonary functional assessment of patients with lung cancer. Eur J Nucl Med Mol Imaging 2006;33:1048-54.

20. Ueda K, Tanaka T, Hayashi M, et al. Compensation of pulmonary function after upper lobectomy versus lower lobectomy. J Thorac Cardiovasc Surg 2011;142:762-7.

21. Ali MK, Mountain CF, Ewer MS, et al. Predicting loss of pulmonary function after pulmonary resection for bronchogenic carcinoma. Chest 1980;77:337-42.

22. Ravikumar P, Yilmaz C, Dane DM, et al. Regional lung growth following pneumonectomy assessed by computed tomography. J Appl Physiol (1985) 2004;97:1567-74;

Cite this article as: Matsumoto R, Takamori S, Yokoyama S, Hashiguchi T, Murakami D, Yoshiyama K, Nishi T, Kashihara M, Mitsuoka M, Hayashida R, Kakuma T, Akagi Y. Lung function in the late postoperative phase and influencing factors in patients undergoing pulmonary lobectomy. $\mathrm{J}$ Thorac Dis 2018;10(5):2916-2923. doi: 10.21037/jtd.2018.05.27 discussion 1549.

23. Baldi S, Ruffini E, Harari S, et al. Does lobectomy for lung cancer in patients with chronic obstructive pulmonary disease affect lung function? A multicenter national study. J Thorac Cardiovasc Surg 2005;130:1616-22.

24. Edwards JG, Duthie DJ, Waller DA. Lobar volume reduction surgery: a method of increasing the lung cancer resection rate in patients with emphysema. Thorax 2001;56:791-5.

25. Sekine $Y$, Iwata T, Chiyo M, et al. Minimal alteration of pulmonary function after lobectomy in lung cancer patients with chronic obstructive pulmonary disease. Ann Thorac Surg 2003;76:356-61. 